Article

\title{
Stomatal Behavior of Cowpea Genotypes Grown Under Varying Moisture Levels
}

\author{
Lawrence Munjonji ${ }^{1, *}$ (D), Kingsley K. Ayisi ${ }^{1}$, Pascal Boeckx ${ }^{2}$ (D) and Geert Haesaert ${ }^{2}$ \\ 1 Risk and Vulnerability Center, University of Limpopo, P Bag X1106, Sovenga 0727, South Africa; \\ kwabena.ayisi@ul.ac.za \\ 2 Faculty of Bioscience Engineering, Ghent University, B-9000 Gent, Belgium; Pascal.Boeckx@ugent.be (P.B.); \\ geert.haesaert@ugent.be (G.H.) \\ * Correspondence: Munjonji@gmail.com; Tel.: +27-79-792-0860
}

Received: 13 October 2017; Accepted: 17 December 2017; Published: 23 December 2017

\begin{abstract}
Drought is a major limitation to crop productivity worldwide. Plants lose most of their water through stomata, thus making stomata an important organ in the control of transpiration and photosynthesis. This study assessed the stomatal behavior of four cowpea genotypes grown under four moisture levels under hot semi-arid conditions. Stomatal conductance $(g s)$ was measured at $47,54,70$ and 77 days after planting (DAP). Biomass and carbon isotope composition $\left(\delta^{13} \mathrm{C}\right)$ were also determined at flowering. Genotype and moisture level significantly influenced gs. Genotypes varied in $g s$ at vegetative stages ( 47 and $54 \mathrm{DAP}$ ) only. TVu 4607 had higher $g s$ under severe drought conditions at both 47 and 54 DAP. On the other hand, moisture level influenced $g s$ at 54 and 70 DAP only. Stomatal conductance was severely restricted in cowpea under both moderate and severe drought conditions as $g s$ was mostly below the threshold $0.10 \mathrm{~mol} \mathrm{~m}^{-2} \mathrm{~s}^{-1}$. Relationships between: biomass and $g s$, and $\delta^{13} \mathrm{C}$ and $g s$ were positive under severe drought only. The findings revealed that cowpea genotypes vary in $g s$ under dry conditions and that the variation is more prominent at vegetative stage, suggesting that cowpea productivity in dry areas could be improved through selection of genotypes that maintain higher $g s$ under dry conditions.
\end{abstract}

Keywords: carbon isotope composition; cowpea; stomatal conductance; water stress

\section{Introduction}

Water use efficiency (WUE) and crop productivity strongly depend on stomatal conductance ( $g s$ ) of the crop. The opening and closing of the stomata, which is mainly affected by water availability [1], not only influence the amount of $\mathrm{CO}_{2}$ that diffuses into the leaf for photosynthesis but also the amount of water lost through the leaf [2]. Thus, the compromise between water loss and carbon gain determines WUE of a crop and is influenced by the stomatal response to environmental conditions [3]. Stomatal conductance thus plays a particularly important role of controlling water loss in crops grown in dry areas.

Cowpea is an important legume for smallholder farmers in arid and semi-arid regions of Africa. It is commonly grown in hot and dry areas where evaporative demand is high. Therefore, understanding the behavior of the stomata in cowpea is vital for improving its productivity and its adaptation to future drier climates.

The occurrence of droughts in semi-arid areas where cowpea is commonly grown is expected to increase [4] and this will negatively affect cowpea productivity. To maintain acceptable levels of crop productivity in such environments, there is a need to develop drought tolerant cultivars that use water efficiently [5]. The improvement of drought resistance in cowpea is only possible if there is a better understanding of its physiological responses to limited water supply. One of the primary 
physiological responses with a significant role in drought resistance is $g s$. Stomatal conductance is also believed to be a reliable integrative indicator of water stress [6] even though patchy gs could present challenges [7,8]. It is also important to develop a proxy for WUE to facilitate breeding.

WUE has been proposed to be strongly related to the adaptation of crops to drought [9] and can be measured as a ratio of biomass accumulation to the amount of water transpired/used. Alternatively, it can also be measured at leaf level as the ratio of photosynthetic rate $(A)$ to $g s$ [10], commonly referred

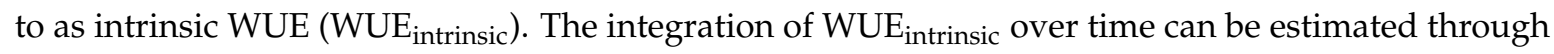
carbon isotope composition $[6,11]$. Carbon isotope composition has also been shown to be related to WUE [12]. According to Bloch, Hoffmann [13], plants with a lower ${ }^{13} \mathrm{C}_{-} \mathrm{CO}_{2}$ discrimination tend to be efficient water users. The advantage of measuring carbon isotope composition is that it provides an integrated measure of the plant's growing conditions as opposed to instantaneous measurements provided by gs measurements.

Against this background, it is, therefore, important to elucidate the role of $g s$ and carbon isotope discrimination on drought resistance and productivity of cowpea. This study therefore seeks to establish (1) how $g s$ in cowpea is influenced by genotype and moisture level (2) how gs evolves with time under varying moisture levels. The study also seeks to establish whether there is any correlation between dry biomass accumulation and $g s$ and whether carbon isotope composition (which provides an integration of $g s$ and $A$ ) is related to cowpea productivity and WUE.

\section{Materials and Methods}

\subsection{Plant Growth Conditions and Experimental Design}

A two-year field research was carried out at the University of Limpopo experimental farm, Syferkuil $\left(23^{\circ} 50^{\prime} \mathrm{S}, 029^{\circ} 41^{\prime} \mathrm{E}\right)$ in the Limpopo Province, South Africa. In the first year, cowpea was planted on the 2 January 2015 while in the second experiment, planting was on the 22 December 2015. The differences in planting dates were mainly a result of logistics. The average daily temperature during the growing season at Syferkuil ranges from 12 to $35^{\circ} \mathrm{C}$.

Four genotypes; IT00K-1263, IT99K-1122, TVu14632 and TVu4607 were used in the experiments and abbreviated as IT1, IT2, TV1 and TV2, respectively. The lines were sourced from the International Institute of Tropical Agriculture (IITA) in Nigeria. The lines were selected from a pool of 91 that were pre-screened earlier for high grain and biomass yield in Limpopo over a period of two years. In the first season, all 91 lines were grown under rain fed conditions and the best eight performing lines in terms of grain and biomass yield were selected. In the subsequent season, the eight lines were further grown under rain fed conditions and four lines with high grain yield and biomass were selected for further investigation. In both pre-screening seasons cowpea was sown later in the season to induce water stress conditions through reduced rainfall.

Cowpea was planted in rows, $0.9 \mathrm{~m}$ apart with in row spacing of $0.20 \mathrm{~m}$, without inoculation and depended on the resident Bradyrhizobia population for nodulation. The plot sizes were $10 \mathrm{~m} \times 10 \mathrm{~m}$ and irrigation was by Rain Bird sprinklers (Rain Bird, Azusa, CA, USA), fitted with Arad M20 water meters (Arad Group, Arad, Israel) to record the amount of water applied. In addition, rain gauges were installed at the center of each plot. Soil moisture was measured three to four times a week using a capacitance sensor; Diviner 2000 (Sentek Technologies, Stepney, Australia) from access tubes installed at the center of each plot. Irrigation was applied when half of the plots under the same moisture level reached the threshold value. The soil was classified as a Chromic Luvisol (Hypereutric) [14]. The soil depth ranges from $60-70 \mathrm{~cm}$, with sandy clay loams overlaying sandy clays and an available water capacity (AWC) of $80 \mathrm{~mm}$.

The four genotypes were examined under four moisture levels in a split-plots and four replications. The main plot treatment was the irrigation level and the subplot, cowpea lines. The four moisture levels were as follows: 
- Well-watered (WW): $25 \%$ soil moisture depletion before recharging to field capacity (FC);

- Moderately well-watered (MW): 50\% soil moisture depletion before recharging to FC;

- Moderate drought (MD): $75 \%$ soil moisture depletion before recharging to $50 \%$ of FC;

- Rainfed (severe drought; SD): the crop depended solely on rainfall. However, in the 2016 season, the plots were irrigated at the beginning to establish the experiments as the rainfall was too low at the start of the season.

Due to unexpected rainfall interferences, the moisture levels could not be maintained throughout the 2016 growing season. However, in the 2015 season, the moisture levels were maintained for most parts of the growing season due to reduced seasonal rainfall and longer drought period experienced. The amounts of water received (irrigation + rainfall) by the crop at flowering and harvesting stages for the different moisture treatments is shown in Table 1. Cowpea grown under water-limited conditions flowered much earlier compared to the cowpea grown under well-watered conditions. These differences were more pronounced in 2015 compared to 2016. In addition, cowpea took longer to reach gravest maturity in 2016 compared to 2015 due to the availability of more moisture.

Table 1. Total amount of water received by cowpea genotypes and the days taken (DAP) to reach flowering and harvesting maturity in 2015 and 2016.

\begin{tabular}{|c|c|c|c|c|c|c|c|c|}
\hline \multirow[b]{3}{*}{ Moisture } & \multicolumn{4}{|c|}{2015} & \multicolumn{4}{|c|}{2016} \\
\hline & \multicolumn{2}{|c|}{ Flowering } & \multicolumn{2}{|c|}{ Harvesting } & \multicolumn{2}{|c|}{ Flowering } & \multicolumn{2}{|c|}{ Harvesting } \\
\hline & $\begin{array}{l}\text { DAP to } \\
\text { Flowering }\end{array}$ & $\begin{array}{c}\text { Irrigation + } \\
\text { Rainfall (mm) }\end{array}$ & $\begin{array}{l}\text { DAP to } \\
\text { Maturity }\end{array}$ & $\begin{array}{c}\text { Irrigation + } \\
\text { Rainfall (mm) }\end{array}$ & $\begin{array}{l}\text { DAP to } \\
\text { Flowering }\end{array}$ & $\begin{array}{c}\text { Irrigation + } \\
\text { Rainfall (mm) }\end{array}$ & $\begin{array}{l}\text { DAP to } \\
\text { Maturity }\end{array}$ & $\begin{array}{c}\text { Irrigation + } \\
\text { Rainfall (mm) }\end{array}$ \\
\hline WW & 60 & 181 & 125 & 348 & 76 & 314 & 140 & 419 \\
\hline MW & 60 & 154 & 113 & 267 & 76 & 314 & 140 & 418 \\
\hline MD & 56 & 112 & 97 & 173 & 69 & 237 & 126 & 312 \\
\hline
\end{tabular}

WW: well-watered; MW: moderately well-watered; MD: medium drought and SD: severe drought. DAP for flowering and maturity are averages of the four genotypes.

The AWC was estimated using the hydraulic properties calculator [15]. Before the first planting, composite top soil samples $(0$ to $30 \mathrm{~cm})$ were analyzed for $\mathrm{pH}$, organic carbon $(\mathrm{OC})$, electrical conductivity (EC) and macronutrients. The soils had a $\mathrm{pH}\left(\mathrm{H}_{2} \mathrm{O}\right)$ of $8.1,500 \mathrm{mg} \mathrm{N} \mathrm{kg}^{-1}, 18.7 \mathrm{mg} \mathrm{P} \mathrm{kg}^{-1}$, $369 \mathrm{mg} \mathrm{K} \mathrm{kg}^{-1}, 1008 \mathrm{mg} \mathrm{Ca} \mathrm{kg}^{-1}, 710 \mathrm{mg} \mathrm{kg}^{-1}, 33 \mathrm{mg} \mathrm{Na} \mathrm{kg}^{-1}$ and OC of $0.5 \%$. The EC measured before the start of the experiments was $82 \mu \mathrm{cm}^{-1}$ with an exchangeable sodium percentage (ESP) of 4 making it a non-saline soil. The soils were then fertilized with single super phosphate (10.5\%) at a rate of $35 \mathrm{~kg} \mathrm{P} \mathrm{ha}^{-1}$. The same rate of $\mathrm{P}$ was applied in the subsequent year.

\subsection{Plant Harvesting and Sample Preparation}

Biomass at $50 \%$ flowering (i.e., time when half of the plants had flowered) was harvested from a $0.9 \mathrm{~m}^{2}$ area (equivalent to four plants per plot) from all plots on the same day in each year while grain yield was determined at harvest maturity from four middle rows of $2 \mathrm{~m}$ length each (equivalent to 40 plants per plot). Shoot biomass at flowering was collected by cutting the main stem at $3 \mathrm{~cm}$ above the ground, leaving small stumps. Root biomass was then sampled by first watering the soil around the stumps to avoid root hair and nodule loss. Basins were made around the harvest area (about $0.36 \mathrm{~m}^{2}$ ) and then watered using canes. Water was applied to the small harvest area only. As described the plots were $100 \mathrm{~m}^{2}$ in size hence the watered area did not disturb the moisture treatments. The watered area was then left for $24 \mathrm{~h}$ to allow infiltration before carefully digging out the stumps using spades. The roots were then washed with water on a sieve to remove bound soil particles and collect root biomass. Shoot and root dry biomass was then determined by oven drying the samples at $65^{\circ} \mathrm{C}$ to constant weight. Grain yield was harvested at full maturity on different days for the different moisture as cowpea reached maturity at different times. The time when the first harvest was done in each year is shown by the big arrows on Figure 1. 

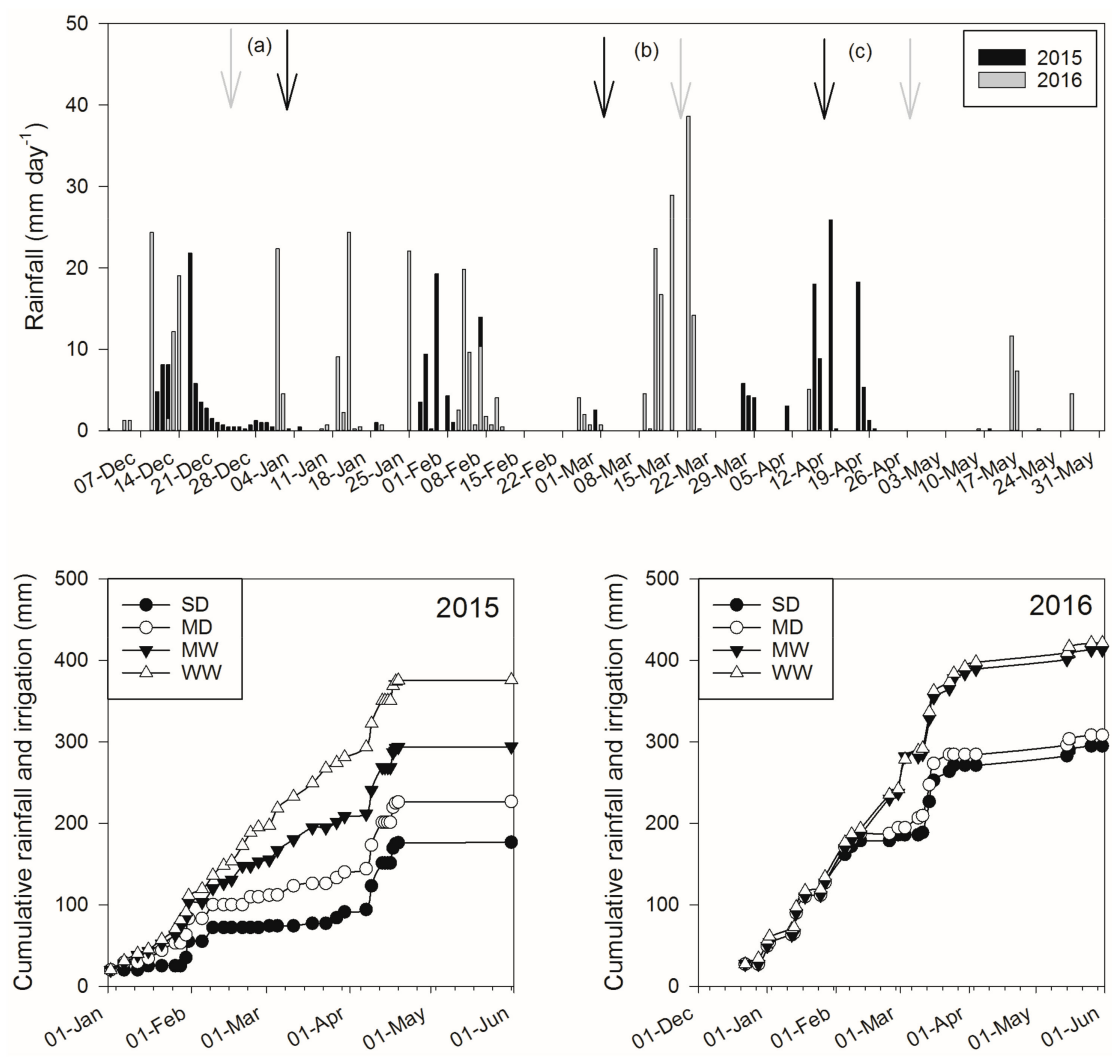

Figure 1. Top panel: Daily rainfall received during the two growing seasons, starting in December of previous year until harvest (2015-black bars and 2016-grey bars). Set of arrows: (a) sowing day (b) biomass collection at 50\% flowering and (c) long arrows first harvesting dates (2015-black arrows; 2016-gray arrows). Bottom panels show cumulative rainfall plus irrigation for the two years (2015 on the left and 2016 on the right).

\subsection{Leaf Gas Exchange Measurements}

Leaf gas exchange (stomatal conductance $(g s)$, photosynthetic rate $(A)$ and transpiration rate $(E)$ ) measurements were carried out using LCi-SD Ultra Compact Photosynthesis System (ADC Bio Scientific, Hoddesdon, UK). The photosynthesis machine does not provide control of $\mathrm{CO}_{2}$, temperature or relative humidity but rather uses ambient conditions. The measured ambient $\mathrm{CO}_{2}$ ranged from 380 to $395 \mathrm{ppm}$, chamber temperature from 30 to $36^{\circ} \mathrm{C}$ while ambient relative humidity averaged from a minimum of $35 \%$ and a maximum of $93 \%$ over the growing period. The measurements were taken four times in the first season on clear sunny days between $11 \mathrm{~h} 00$ and $13 \mathrm{~h} 00$. The measurements were taken at 47, 54, 70, and 77 days after planting (DAP) in 2015. In 2016, the measurements were taken only once at $70 \mathrm{DAP}$ due to malfunctioning of the machine. The measurements were done on a single youngest fully matured leaf per plot.

\subsection{Isotope Analyses}

For isotope analyses, five to ten young fully grown leaves (depending on the size) were randomly sampled from different plants per plot at $50 \%$ flowering. The leaves were dried at $65^{\circ} \mathrm{C}$ to constant weight and ground to a fine powder using a ZM200 mill (Retsch, Haan, Germany). The ${ }^{13} \mathrm{C} /{ }^{12} \mathrm{C}$ isotope compositions of the leaves were analyzed using an Automated Nitrogen Carbon Analyser-Solid and Liquids (ANCA-SL) (SerCon, Crewe, UK) interfaced with an Isotope Ratio Mass Spectrometer (IRMS) 
(20-20, SerCon, Crewe, UK). The isotope composition was reported as $\delta^{13} \mathrm{C}$ in $\%$ using Vienna Pee Dee Belemnite $(\mathrm{V}-\mathrm{PDB})$ as international standard $\left(\mathrm{R}_{\text {standard }}\right)$ and calculated using the formula below:

$$
\delta^{13} \mathrm{C}_{\text {sample }}=\left(\frac{\mathrm{R}_{\text {sample }}}{\mathrm{R}_{\text {standard }}}-1\right) \times 1000
$$

\subsection{WUE Determination}

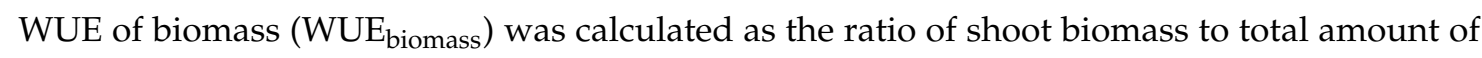
water used. The total amount of water added was obtained from the summation of the rain gauge recordings from planting to flowering. At leaf level, intrinsic WUE (WUE $\mathrm{E}_{\text {intrinsic }}$ ) was calculated as follows: $\mathrm{WUE}_{\text {intrinsic }}=A / g s$ where $A$ is the photosynthetic rate, and $g s$ is the stomatal conductance. $A$ and $g s$ were obtained from the measurements of the Photosynthesis System described under 2.3.

\subsection{Statistical Analyses}

The analysis was conducted in accordance with the standard procedure for analysis of variance (ANOVA) of a split plot design with irrigation as the main plot and genotypes as sub-plots [16]. The ANOVA was performed to calculate the effects of moisture level, genotype and time (i.e., DAP) on the studied parameters. Where the interaction effect was not significant, data was split according to moisture level and analyzed for the effect of genotype at each moisture level (for some parameters). Post hoc multiple comparisons for observed means was done using Tukey and different means were denoted by ${ }^{*}, * *$ or ${ }^{* * *}$ for significance levels $p \leq 0.05, p \leq 0.01$ and $p \leq 0.001$, respectively. Bivariate Pearson Correlation was carried out to assess the relationship between $g s$ and $\delta^{13} \mathrm{C}$ and between $g s$ and biomass. All data were analyzed using the SPSS 20 statistical package (SPSS, Armonk, NY, USA).

\section{Results}

\subsection{Rainfall Distribution and Amount}

The distribution of daily rainfall received during the two growing seasons as well as the cumulative amount of water applied is shown on Figure 1. Time to physiological maturity varied with moisture levels in both years. The total amount of water received from planting to last harvesting was $121 \mathrm{~mm}$ in 2015 and $299 \mathrm{~mm}$ in 2016 (Table 1). No significant rains were received in the immediate period before and after planting in 2016, hence the crop was irrigated to establish the experiment. At the time of biomass collection (short arrows), a total of $73 \mathrm{~mm}$ was received in 2015 while at the same stage $218 \mathrm{~mm}$ (rainfall + irrigation) had been received in 2016. Furthermore, the rainfall distribution differed between the two seasons. A longer mid-season dry period was experienced in 2015 compared to 2016. Soon after the dry period in 2016, $126 \mathrm{~mm}$ of rain was received in ten days when the cowpea was still flowering while much of the late rain received in 2015 came when most of the cowpea had reached physiological maturity. The cumulative amount of rainfall and irrigation differed with moisture levels in 2015 as shown by the bottom left panel. However, in 2016, differences were only observed between well-watered (WW and MW) and water-limited conditions (MD and SD). It must be noted that there were some significant rains received after harvesting of cowpea under MD and SD in 2015.

\subsection{Genotypic Variation in Stomatal Conductance with Time and Moisture Level}

Stomatal conductance measured in 2015 varied with genotype, moisture level, DAP and the combined effect of moisture and DAP. Due to the interaction between moisture level and DAP, Figure 2 shows $g s$ data separated according to moisture level and showing the effects of genotype and DAP. Genotypes varied in $g s$ before flowering i.e., at 47 and 54 DAP but neither at flowering (70 DAP) nor just after flowering (77 DAP) (Figure 2). Similarly, no genotypic variations in gs were observed in 2016, where $g s$ measurements were only carried out at 70 DAP (results not shown). At both 47 and 54 DAP, 
significant variations in $g S$ were mainly observed under limited water supply (MD and SD). Under SD conditions, genotype TV2, had significantly higher gs compared to the other genotypes at 47 DAP while it only differed with IT2 under the same moisture level at 54 DAP. However, under MW, genotype IT1 performed much better than the other genotypes at 47, 54 and 70 DAP. Moisture levels on the other hand, significantly influenced $g s$ at 54 and 70 DAP but had no influence at 47 and 77 DAP (Figure 2). Generally, gs was higher under well-watered conditions (WW and MW) compared to water-limited conditions (MD and SD). At 54 DAP, $g s$ was higher under WW compared to both MD and SD but did not differ with MW. A similar trend was also observed at 70 DAP. Figure 2 also shows how $g s$ of the genotypes evolved with DAP at each moisture levels with a control line at $0.10 \mathrm{~mol} \mathrm{~m}^{-2} \mathrm{~s}^{-1}$ showing the threshold value below which photosynthesis is believed to be affected as described by Flexas et al. [17]. The figure shows that under WW, gs was above the threshold at 47, 54 and 70 DAP and was only below the threshold at 77 DAP. Under MW, only IT1 maintained $g s$ at above the threshold until 70 DAP. However, under SD, all genotypes had gs below the threshold except for TV2 at 47 DAP. Genotype TV2, even though below $0.10 \mathrm{~mol} \mathrm{~m}^{-2} \mathrm{~s}^{-1}$, it maintained a relatively higher $g s$ compared to the genotypes. However, under SD, gs was mostly below $0.05 \mathrm{~mol} \mathrm{~m}^{-2} \mathrm{~s}^{-1}$.
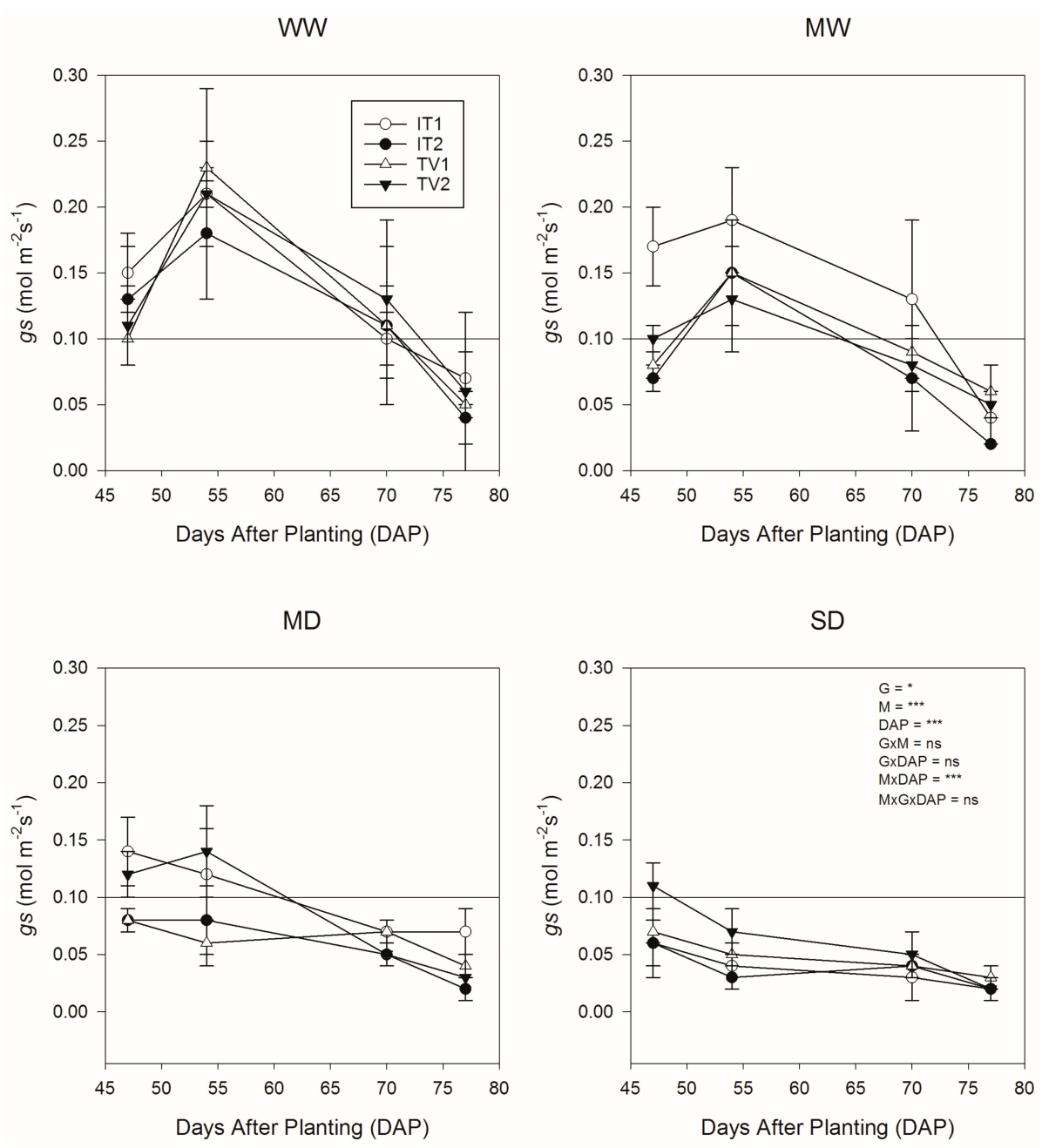

Figure 2. Variation in genotypic stomatal conductance with DAP at different moisture levels (well-watered (WW), moderately well-watered (MW), moderate drought (MD) and severe drought (SD) for data measured in 2015. IT1, IT2, TV1 and TV2 are the genotypes. The ANOVA table shows the effects of genotypes (G), Moisture level (M), Time of measurement as DAP as well as their interaction effects. Error bars are stander error of mean. The line at $0.10 \mathrm{~mol} \mathrm{~m}^{-2} \mathrm{~s}^{-1}$ is a control line showing the threshold value below which photosynthesis is affected as described by Flexas et al. [17]. 


\subsection{Evolution of Leaf Gas Exchanges with Time under the Four Moisture Levels}

The progression of cowpea mean stomatal conductance $(g s)$, photosynthetic rate $(A)$, transpiration rate $(E)$ and the ratio of inter-cellular $\mathrm{CO}_{2}$ concentration to ambient $\mathrm{CO}_{2}(\mathrm{ci} / \mathrm{ca})$ (averaged across genotypes) with DAP is shown on Figure 3. Moisture level significantly influenced the progression of measured gas exchange parameters. Cowpea grown under well-watered conditions had high values of the $g s, A$ and $E$ compared to those grown under water-limited conditions. At higher moisture levels (WW and MW), an initial increase in $g s, A$, and $E$ was observed from 47 to 54 DAP followed by a gradual decrease from 54 through 70 to 77 DAP. At lower moisture levels (particularly under $\mathrm{SD})$, no initial increase in $g s, A$, and $E$ was observed but rather a steady decrease with time from the first measurement (47 DAP) to the last (77 DAP). Differences in $g s, A$, and $E$ resulting from the effect of moisture levels were more distinct at 54 DAP. Differences in $g s, A$, and $E$ were mainly significant between WW and SD. Remarkably, even though high moisture levels were maintained under WW, gs, $A$, and $E$ still decreased with DAP from 54 DAP onwards. The variation of $A$ and $g s$ with time and moisture levels was very similar and strongly related (Table 2).

gs

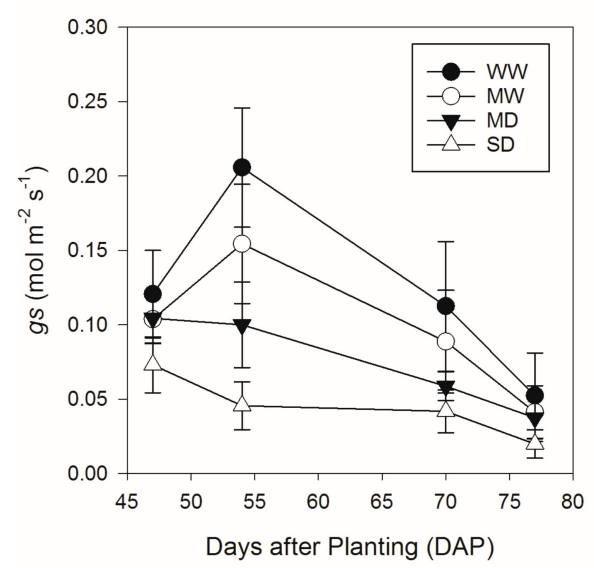

E

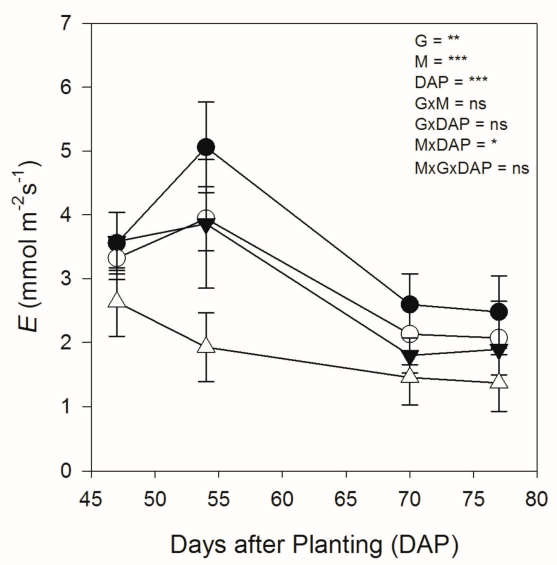

A

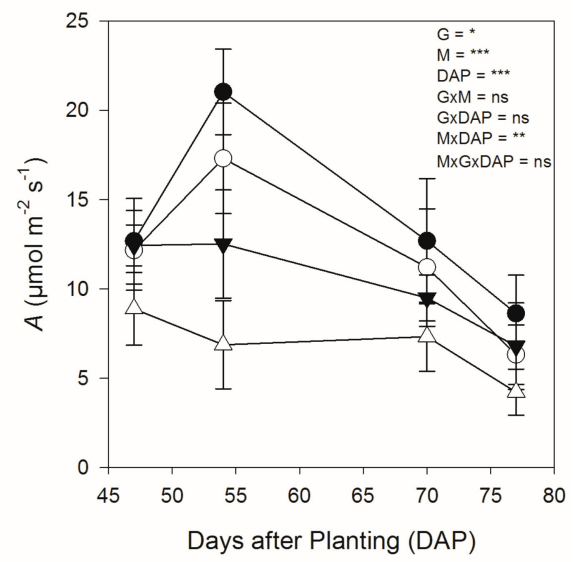

ci/ca

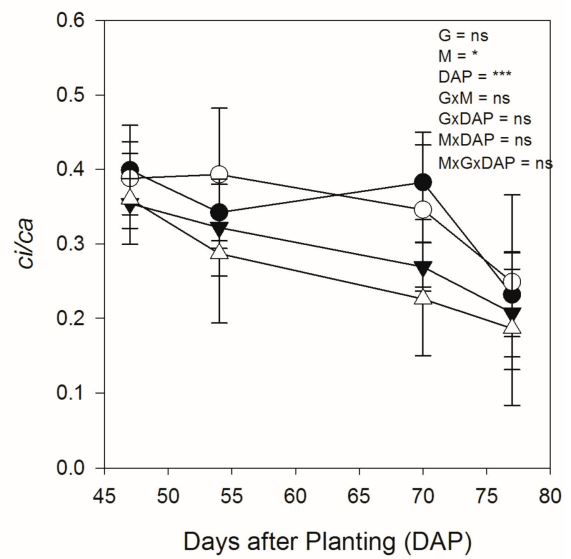

Figure 3. Mean stomatal conductance $(g s)$, photosynthetic rate $(A)$, transpiration $(E)$, and ratio of intercellular $\mathrm{CO}_{2}$ concentration ( $\left.c i\right)$ to ambient $\mathrm{CO}_{2}$ concentration $(c a)$ of four cowpea genotypes under four moisture levels (well-watered (WW), moderately well-watered (MW), moderate drought (MD) and severe drought (SD)) measured at 47, 54, 70 and 77 days after planting (DAP). Errors bars indicate standard error of means. 


\subsection{Relationship between gs Measured at $47 \mathrm{DAP}$, Biomass and $\Delta^{13} \mathrm{C}$}

Figure 4 shows the relationship between $g s$ and biomass, and between $g s$ and $\delta^{13} C$ during the early growth stages of cowpea (47 DAP) as affected by the four moisture levels. Figure 5 on the other hand shows the relationships of genotypic averages demonstrating how $g s$ of the four genotypes was related to biomass, $\delta^{13} \mathrm{C}$, root biomass and grain yield. The results showed no significant relationships between dry biomass accumulated prior to flowering (i.e., $47 \mathrm{DAP}$ ) and $g s$ measured under WW, MW and MD conditions. A similar relationship was also observed with leaf $\delta^{13} \mathrm{C}$. However, under rain fed (SD), positive relationships were observed between $g s$ and dry biomass $\left(\mathrm{r}^{2}=0.58, p<0.05\right)$ as well as between $g s$ and $\delta^{13} \mathrm{C}$ of leaves sampled at flowering stage $\left(\mathrm{r}^{2}=0.60, p<0.05\right)$. Cowpea grain yield, was also positively related to $g s$ at 47 DAP under SD $\left(r^{2}=0.50, p<0.05\right)$ and under WW $\left(r^{2}=0.64\right.$, $p<0.01)$. The overall relationships: $g s$ and biomass; $g s$ and root biomass; $g s$ and grain yield were mostly positive when data for all moisture levels were combined while that of $\delta^{13} \mathrm{C}$ and $g s$ was mostly negative (Figure 5). Similar relationships were also observed with $g s$ measurements taken at 70 DAP (Figure A1). Where relationships were significantly positive, genotype TV2 performed much better compared to the others. Figure 5A,D shows that TV2 had significantly higher aboveground biomass, root biomass and $g s$ under SD conditions. In Table 2 the relationship between $g s$ measured at 70 DAP and $\delta^{13} \mathrm{C}$ was strongly negative in both years $\left(2015=-0.49^{* *}\right.$ and $\left.2016=-0.78^{* *}\right)$.
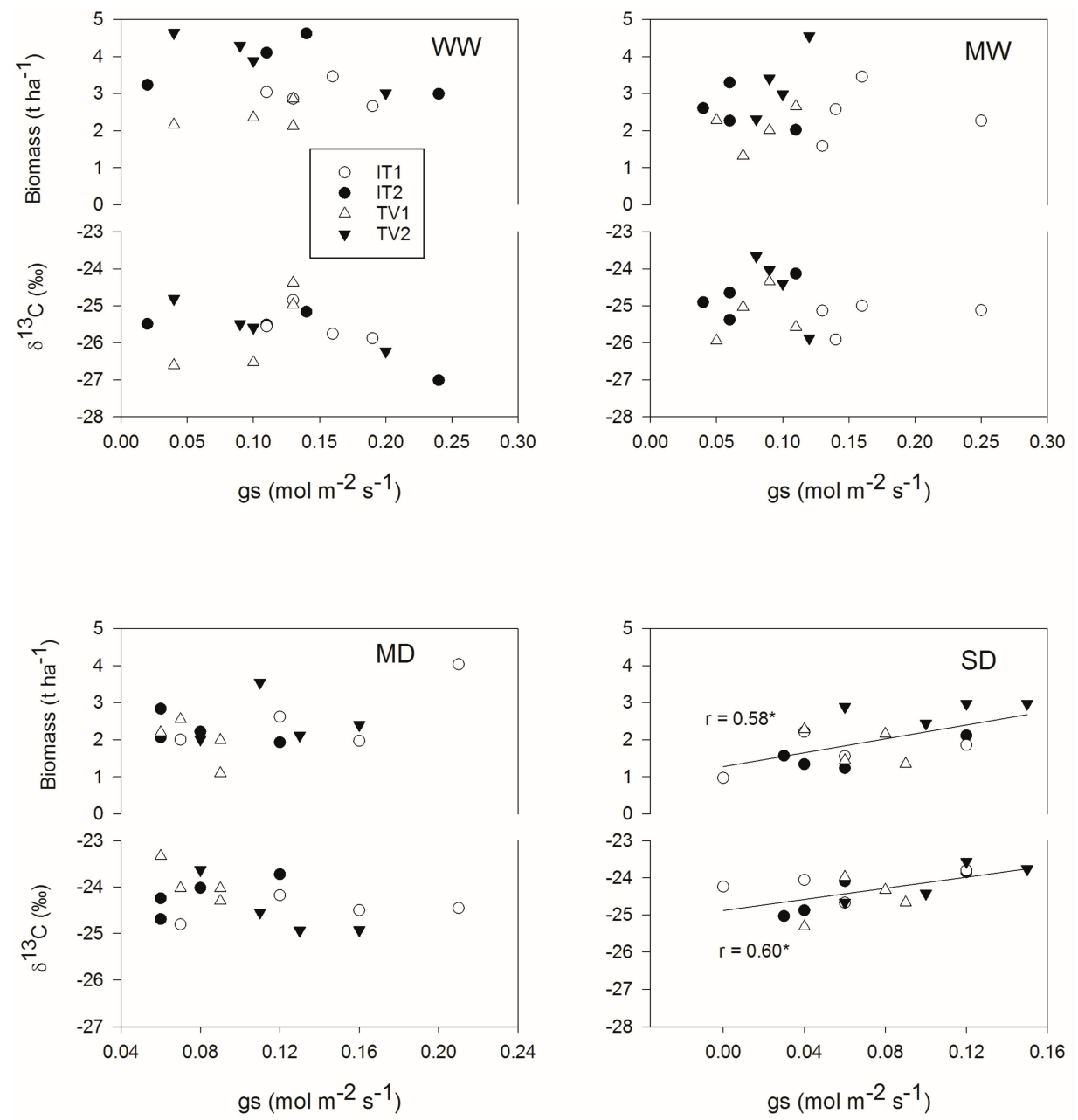

Figure 4. The relationship between stomatal conductance $(g s)$ measured at $47 \mathrm{DAP}$ and biomass accumulated at flowering and as well leaf $\delta^{13} \mathrm{C}$ measured at flowering. 
A

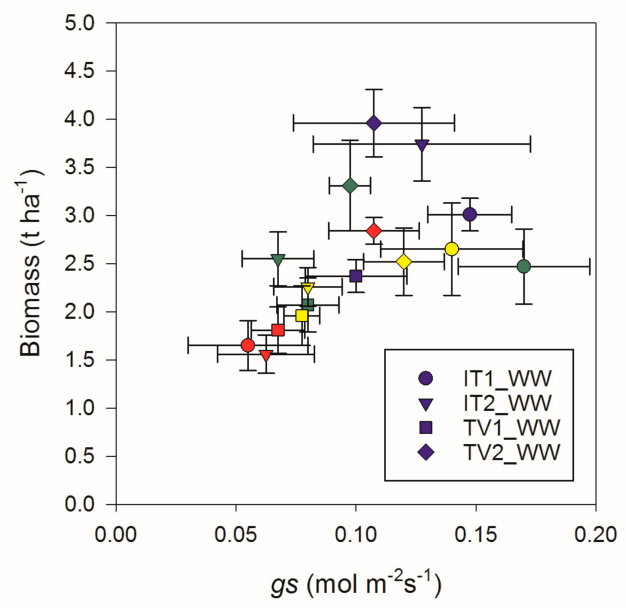

C

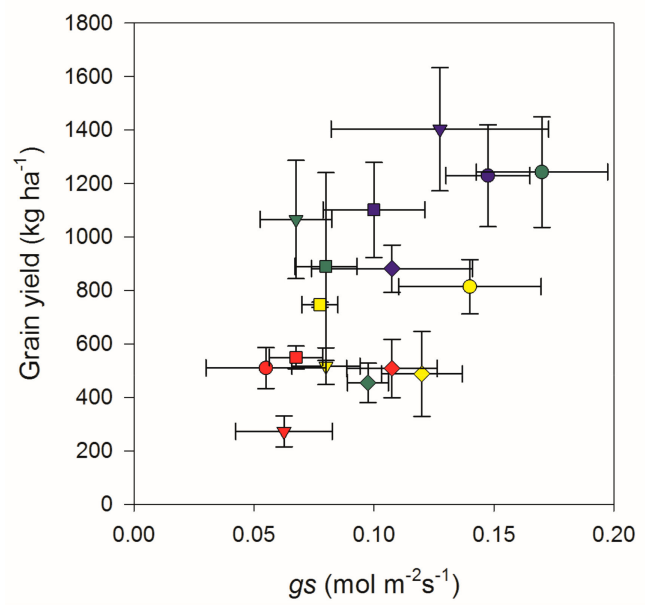

B

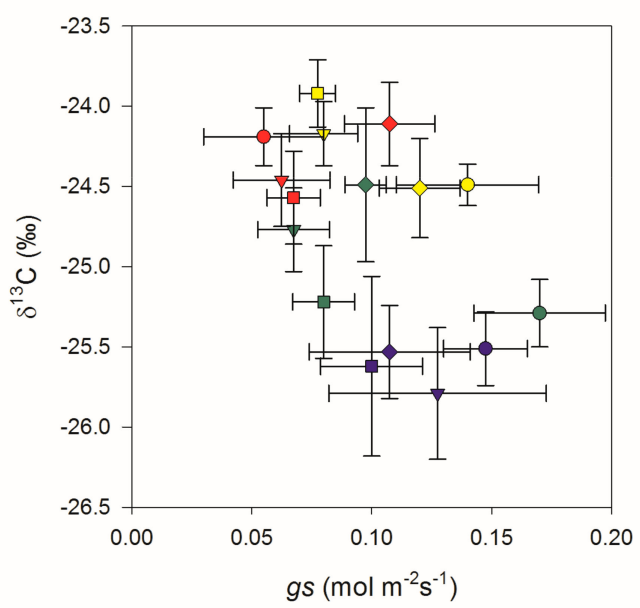

D

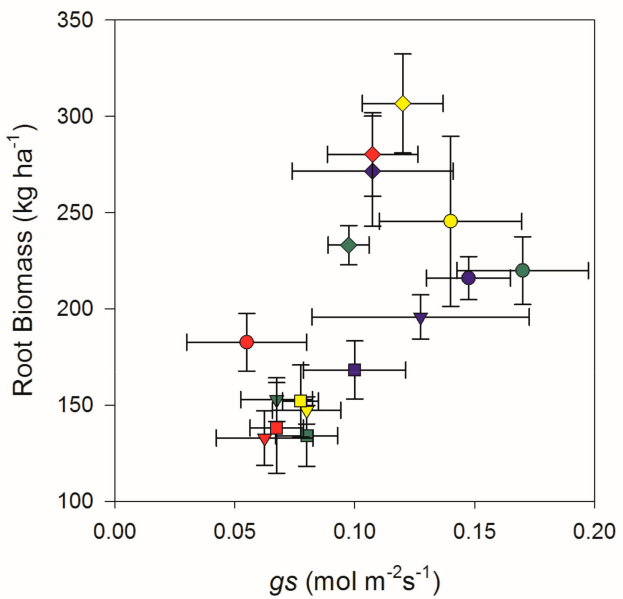

Figure 5. The relationship between genotypic means of stomatal conductance ( $g s)$ measured at 47 DAP and mean biomass (A), $\delta^{13} \mathrm{C}(\mathbf{B})$, root biomass (at flowering) $(\mathbf{C})$ and grain yield (D). Means were calculated per moisture level i.e., blue for well-watered; green for moderate well-watered; yellow for moderate drought and red for severe drought. Symbols: circle for genotype IT1, triangle for IT2, rectangle for TV1, and diamond for TV2.

\subsection{Genotypic Variation in $\Delta^{13} c$ with Moisture Level}

The variation in $\delta^{13} \mathrm{C}$ measured in leaves at the flowering stage is shown on Figure 6. The results show that moisture level significantly influenced leaf $\delta^{13} \mathrm{C}$ in both seasons $(2015$ and 2016), but genotypic effects were not observed. No differences in leaf $\delta^{13} \mathrm{C}$ values were observed for cowpea grown under MD and SD in both seasons. In both seasons, there were clear differences between leaf $\delta^{13} \mathrm{C}$ grown under well-watered conditions (WW and $\mathrm{MW}$ ) and those under water-limited conditions (MD and SD). Thus, cowpea discriminated more against ${ }^{13} \mathrm{C}_{-}-\mathrm{CO}_{2}$ when soil moisture was more readily available compared to when the soil moisture was limited, resulting in more negative $\delta^{13} \mathrm{C}$ values being observed under well-watered conditions. In the first season, differences in leaf $\delta^{13} \mathrm{C}$ values were also observed between WW and MW. In 2015, average $\delta^{13} \mathrm{C}$ values were $-25.6 \%$ under WW and $-24.3 \%$ under SD while in 2016 the averages were $-26.9 \%$ under WW and $-24.7 \%$ under SD. Due to the higher rainfall received in 2016, cowpea discriminated more against ${ }^{13} \mathrm{C}$ in 2016 compared to 2015. 

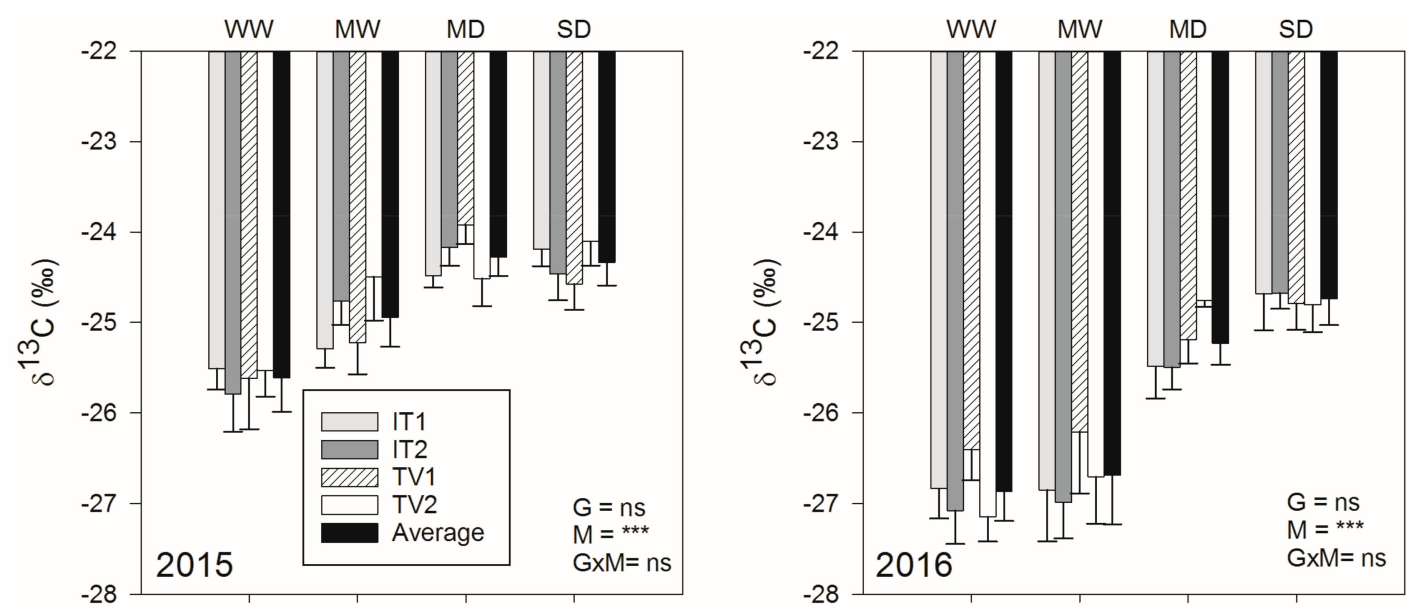

Figure 6. Influence of moisture levels on genotypic $\delta^{13} \mathrm{C}$ measured in leaves sampled, at flowering stage in 2015 and 2016. Average is mean of all genotypes at a particular moisture level. Asterisks show significance: ${ }^{* *}$ for $p \leq 0.001$.

\subsection{WUE biomass and $W U E_{\text {intrinsic }}$ as Influenced by Moisture Level}

WUE $_{\text {biomass }}$ varied with moisture level in 2015 but not in 2016 (Figure 7). Likewise, genotypes had a significant effect on WUE $E_{\text {biomass }}$ only in the 2015 growing season and not in 2016. The interaction effect between moisture level and genotype was not significant in both years. In 2015, a general increase in mean $W_{U E} E_{\text {biomass }}$ with decreasing moisture level was observed where $W U E_{\text {biomass }}$ was higher under SD followed by MD and then MW and WW. Average WUE biomass of $26.8 \mathrm{~kg} \mathrm{ha}^{-1} \mathrm{~mm}^{-1}$ was observed in cowpea grown under SD compared to $18.0 \mathrm{~kg} \mathrm{ha}^{-1} \mathrm{~mm}^{-1}$ observed under WW. Genotypic variations in WUE biomass were observed in 2015 and where only significant under WW and SD. Under SD, TV2 had the highest WUE biomass of $38.6 \mathrm{~kg} \mathrm{ha}^{-1} \mathrm{~mm}^{-1}$ while the other three genotypes did not vary with $W_{U E} E_{\text {biomass }}$ values ranging from 21.4 to $24.8 \mathrm{~kg} \mathrm{ha}^{-1} \mathrm{~mm}^{-1}$. Under

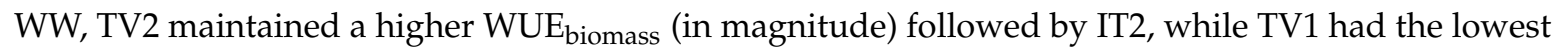

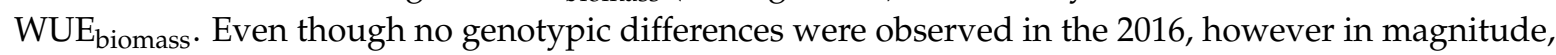
TV1 consistently had the lowest WUE $E_{\text {biomass }}$ under all moisture level. On average, WUE $E_{\text {biomass }}$ was significantly lower in 2016 compared to that of 2015. When data for all moisture levels were

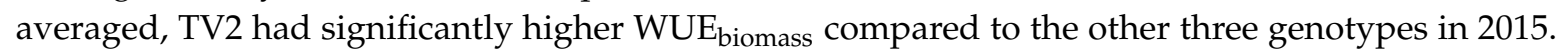
When correlated to the measured gas exchanges, $W E_{\text {biomass }}$ did not show any significant relationship with the measured gas exchange parameters in both seasons (Table 2). No significant relationship was also observed between $W_{U E} E_{\text {intrinsic }}$ and $W_{U E} E_{\text {biomass }}$.

$W_{\text {intrinsic }}$ was also influenced by moisture levels in both seasons. No genotypic differences were observed and the interaction between moisture and genotype was also not significant. WUE $E_{\text {intrinsic }}$ was higher under water-limited conditions (MD and SD) compared to well-watered conditions (MW and WW). In 2015, further differences were also observed between MD and SD. WUE $E_{\text {intrinsic }}$ ranged from 120 to $200 \mu \mathrm{mol} \mathrm{mol}^{-1}$ in 2015 while in 2016 it ranged from 133 to $189 \mu \mathrm{mol} \mathrm{mol}^{-1}$. Genotypes did not vary in $W_{U E} E_{\text {intrinsic }}$ at each moisture level and this was observed in both seasons. Even when data for all moisture levels were combined the genotypes still did not show any differences in WUE intrinsic as was observed with $W_{E_{\text {biomass }} \text {. WUE }} \mathrm{E}_{\text {intrinsic }}$ was also negatively related to $g s, A$, E and $c i / c a$ in both seasons (Table 2). In addition, $\mathrm{WUE}_{\text {intrinsic }}$ was positively related to $\delta^{13} \mathrm{C}$. 
Table 2. Correlation among gas exchange parameters and $W_{U E} E_{\text {intrinsic }}, W E_{\text {biomass, }}$ and $\delta^{13} \mathrm{C}$ in 2015 and 2016 measured at 70 DAP.

\begin{tabular}{|c|c|c|c|c|c|c|}
\hline 2015 & $g s$ & $A$ & $E$ & $c i / c a$ & WUE $_{\text {intrinsic }}$ & WUE $_{\text {biomass }}$ \\
\hline$A$ & $0.89 * *$ & & & & & \\
\hline$E$ & $0.97 * *$ & $0.89 * *$ & & & & \\
\hline$c i / c a$ & $0.30 *$ & -0.06 & $0.30 * *$ & & & \\
\hline WUE $_{\text {intrinsic }}$ & $-0.46^{* *}$ & -0.22 & $-0.42 * *$ & $-0.67 * *$ & & \\
\hline WUE $_{\text {biomass }}$ & -0.19 & -0.18 & -0.08 & 0.10 & 0.09 & \\
\hline$\delta^{13} \mathrm{C}$ & $-0.49 * *$ & $-0.38^{* *}$ & $-0.41 * *$ & $-0.23 *$ & $0.34 * *$ & $0.31 *$ \\
\hline 2016 & $g s$ & $A$ & $E$ & $c i / c a$ & WUE $_{\text {intrinsic }}$ & WUE $_{\text {biomass }}$ \\
\hline$A$ & $0.90 * *$ & & & & & \\
\hline$E$ & $0.94 * *$ & $0.91 * *$ & & & & \\
\hline$c i / c a$ & -0.01 & $-0.35^{* *}$ & -0.11 & & & \\
\hline $\mathrm{WUE}_{\text {intrinsic }}$ & $-0.60 * *$ & $-0.31 * *$ & $-0.54 * *$ & $-0.54 * *$ & & \\
\hline WUE $_{\text {biomass }}$ & 0.11 & 0.15 & 0.09 & -0.02 & -0.05 & \\
\hline$\delta^{13} \mathrm{C}$ & $-0.78 * *$ & $-0.72 * *$ & $-0.74^{* *}$ & -0.04 & $0.48 * *$ & $-0.26 *$ \\
\hline
\end{tabular}

Bold values show significant correlations. Asterisks show significance: ${ }^{*}$ for $p<0.05$ and ${ }^{* *}$ for $p<0.01$. Data averaged for all moisture levels.
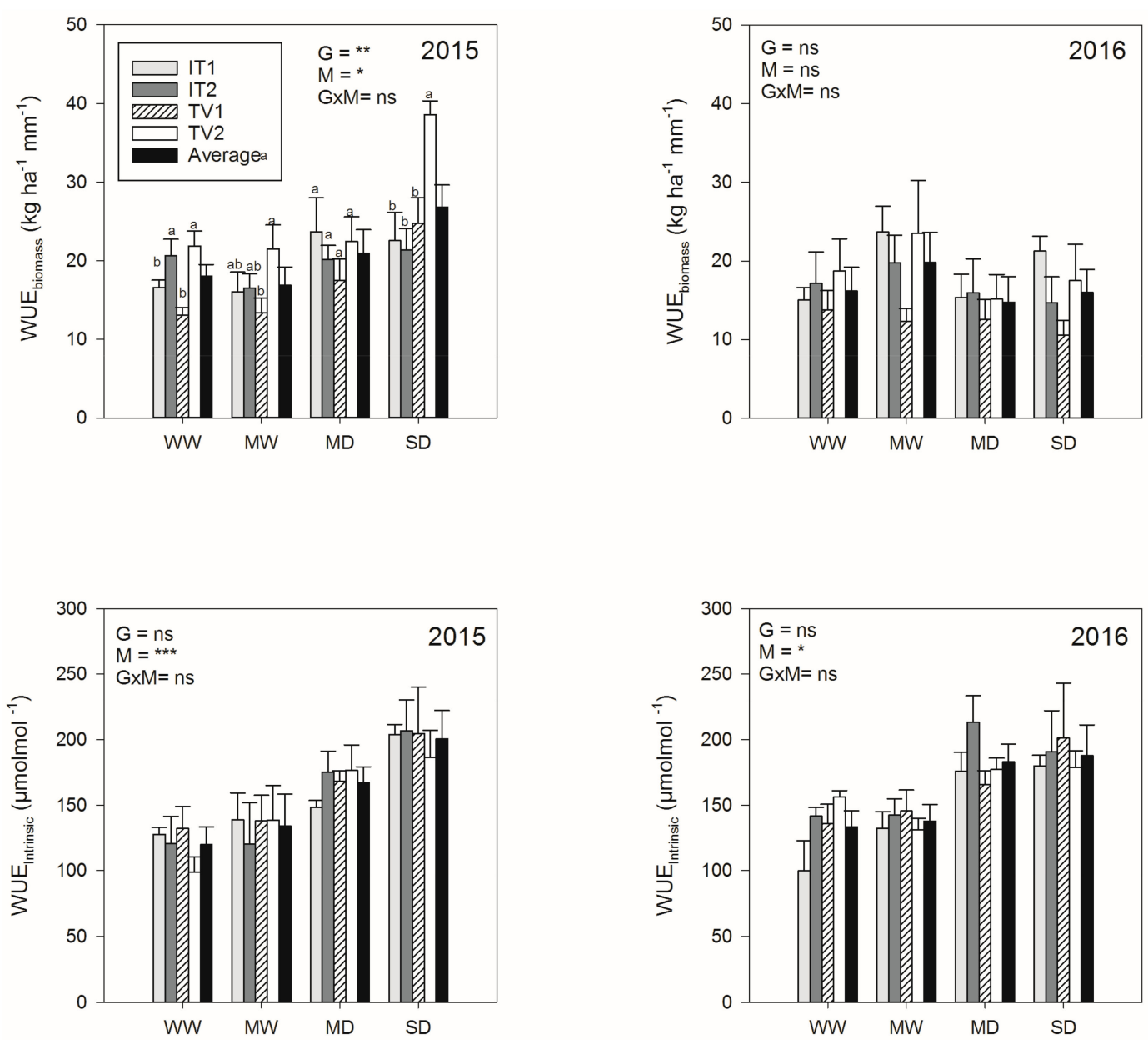

Figure 7. The effect of moisture levels on biomass WUE and Intrinsic WUE of the four studied genotypes measured in 2015 and 2016. Letters show differences among the genotypes at each moisture level (different letters represent significant differences). Asterisks show significance: ${ }^{*}$ for $p<0.05,{ }^{* *}$ for $p<0.01$ and $^{* * *}$ for $p \leq 0.001$. 


\section{Discussion}

\subsection{Variation in Leaf Gas Exchange with Genotype, Moisture Level and DAP}

The study has shown that soil moisture significantly influences leaf gas exchanges in cowpea. Stomatal conductance, $A$ and $E$ were found to be high under higher moisture level compared to lower moisture levels (Figures 2 and 3). Such results were expected and agree with the findings of similar studies [6]. It was also interesting to note that genotypes only varied in $g s$ during the early growth stages but not in the later stages. A plausible explanation for such a variation could be differences in root establishment, where genotypes that establish their roots faster would have much more access to water, resulting in high leaf water content and hence higher gs. Agbicodo, Fatokun [18] reported that plants that maintain higher tissue water potential under low water availability can do so by developing efficient root system that maximizes on water uptake.

Accordingly, it can be postulated that the high $g s$ of TV2 at 47 and 54 DAP under SD (Figure 2) may have resulted from a stronger and a more efficient rooting system (Figure 5D) that enabled it to tap water efficiently early in its growth. Even though TV2 was superior in biomass and root biomass under $\mathrm{SD}$, the grain yield observed at the same moisture level was not congruent with the high biomass observed. Interestingly, at both 47 and 54 DAP genotypes did not vary in $g s$ under WW conditions but showed much variation under lower moisture levels (MW, MD and SD). This could probably be due to the easily available moisture that allowed the genotypes to absorb enough moisture to keep stomata open. This probably suggests that, $g s$ variation in cowpea genotypes may be more determined by root characteristics rather than by leaf characteristics. Under MW and MD, IT1 and TV2 consistently revealed higher gs compared to the other two genotypes (IT2 and TV1). However, under SD, TV2 maintained relatively higher values of $g s$, which were significant at 47 DAP. The results suggest that TV2 probably has the capacity to establish an efficient rooting system very early in the season. In a separate study, TV2 was found to have significantly higher root biomass compared to the other genotypes [19].

Genotypic differences observed in $g s$ under low water availability could be due to differences in the response mechanisms to water deficit. Genotypes with higher capacity to establish efficient rooting system, may show drought tolerance by maintaining relatively higher $g s, E$ an $A$ while those weakly established rooting system, may show drought avoidance by closing their stomata, hence low $g_{s}, E$ and $A$. IT1 and TV2 displayed strong drought tolerance tendencies under moderate drought (MD) at 47 and 54 DAP. Stomatal conductance of TV2 under MD was similar to its $g s$ under MW while other genotypes had significantly lower $g s$ at MD compared to MW. Stomata of cowpea are also known to be sensitive to soil drying [9], and thus the cowpea plant normally exhibits drought avoidance mechanism [20,21]. The drought avoidance mechanism could explain lower $g s$ across all moisture levels exhibited by IT1, IT2 and TV1 at 54 DAP.

While genotypic differences in $g s$ were observed at 47 and 54 DAP, the soil moisture effect was observed at 54 and 70 DAP (Figure 2). The lack of moisture level effect at 47 DAP is difficult to explain but the differences might have been masked by the higher $g s$ displayed by TV2 and IT1 under MD and SD. The lack of moisture level effect on $g s$ at 77 DAP was probably due to crop aging. Stomata conductance values observed at 77 DAP were significantly low, mostly below $0.05 \mathrm{~mol} \mathrm{~m}^{-2} \mathrm{~s}^{-1}$ (Figures 2 and 3). Figure 3 shows a gradual decrease in $g s$ with DAP even under WW, which supports the idea of plant aging. In addition, stomata are generally known to be more open early in the season than at its end [22] hence the decrease of $g s$ with DAP. Another interesting observation was the $g s$ observed under WW in this study were relatively lower than those observed in intercropped sorghum and cowpea [23] and in sugar beet [13]. However, they were in the same range as those reported by [24] in cowpea and by [25] in wheat.

The strong relationship observed between $g s$ and $A\left(\mathrm{r}^{2}=0.90, p<0.01\right)$ suggests that $\mathrm{CO}_{2}$ assimilation in cowpea is controlled by stomatal effects. However, the water stress may not have been severe enough to induce non-stomatal effects on photosynthetic processes. The control of $g s$ on $A$ 
is also confirmed by the identical evolution of $A$ and $g s$ with time (Figure 3). Similar results have also been reported in other legume studies [26]. Transpiration rate related strongly with $g s\left(\mathrm{r}^{2}=0.97\right.$, $p<0.01,2015$ season). Flexas et al. [17], reported that photosynthesis is affected when $g s$ goes below $0.10-0.15 \mathrm{~mol} \mathrm{~m}^{-2} \mathrm{~s}^{-1}$. In this study, cowpea grown under rain fed conditions (SD) and under MD had $g s$ values lower than $0.10 \mathrm{~mol} \mathrm{~m}^{-2} \mathrm{~s}^{-1}$ for most of their growing period (Figures 2 and 3). This, therefore, suggests that cowpea grown in semi-arid regions are likely photosynthesizing at sub-optimal levels throughout their life cycle. In addition, Table 1 shows that time to flowering and maturity were shortened by water availability. As a result, biomass and grain yield observed in 2015 were significantly lower under SD, an indication of the suppressed photosynthetic rate as well limited time for biomass accumulation and grain filling. Thus, improvement in cowpea stomatal conductance could increase productivity of cowpea under dry conditions. TV2 and IT1 where the only genotypes that maintained $g s$ values above $0.10 \mathrm{~mol} \mathrm{~m}^{-2} \mathrm{~s}^{-1}$ under moderate drought (MD) until 54 DAP.

$\delta^{13} \mathrm{C}$, which provides an integration of the environmental conditions during the period of $\mathrm{CO}_{2}$ assimilation [6], differed with moisture level. $\delta^{13} \mathrm{C}$ values were more negative under well-watered conditions compared to water-limited conditions, which corroborates the findings of many other studies on $C_{3}$ plants $[13,27,28]$. Less negative $\delta^{13} \mathrm{C}$ values under $\mathrm{SD}$ were attributed to lower ${ }^{13} \mathrm{C}$ discrimination due to the partial closure of the stomata occurring under soil drying. The influence of $g s$ and $A$ on $\delta^{13} \mathrm{C}$ is confirmed by the strong negative relationship between $\delta^{13} \mathrm{C}$ and, $A$ and $g s$ (Table 2). The relationship between $g s$ at $47 \mathrm{DAP}$ and $\delta^{13} \mathrm{C}$ showed a positive relationship under SD only (Figure 4). The positive relationship seems to suggest the existence genotypic variation in leaf $\delta^{13} \mathrm{C}$ of cowpea grown under SD conditions, whereby genotypes that show higher $g s$ would have less negative $\delta^{13} \mathrm{C}$ values. However, the observed results did not show significant genotypic variation in $\delta^{13} \mathrm{C}$ under SD (Figure 6). Figure 2 shows that TV2 had significantly higher $g s$ under SD at $47 \mathrm{DAP}$ but this did not translate to significantly higher $\delta^{13} \mathrm{C}$ (Figure 6).

\subsection{Relationships of $W U E_{\text {biomass }}$ and $W U E_{\text {intrinsic }}$ as Influenced by Moisture Level}

Higher WUE is regarded as an important factor in improving crop performance under water-limited conditions [29]. WUE can be measured or estimated in several ways as described by Tambussi, Bort [11]. In this study, WUE was measured in terms of: biomass accumulation (WUE biomass); as gas exchange (WUE $E_{\text {intrinsic }}$ ) and estimated $\delta^{13} \mathrm{C}$ data. The results showed strong influence of moisture level on all three $\left(W U E_{\text {intrinsic }}, W U E_{\text {biomass }}\right.$ and $\left.\delta^{13} \mathrm{C}\right)$. It was observed that $W U E_{\text {intrinsic }}, W E_{\text {biomass }}$ and $\delta^{13} \mathrm{C}$ were all higher under water-limited conditions (Figures 6 and 7) agreeing with the findings of Bloch, Hoffmann [13] who also found higher WUE under water-limited conditions. However, other studies are contrary to such findings [30]. The lack of differences in WUE $\mathrm{biomass}_{\text {in }} 2016$ may be attributed to the relatively higher rainfall received in that year. It is believed that under well-watered conditions plants continue to assimilate carbon even when evaporative demand is very high resulting in higher losses of water per carbon gained, leading to lower $\mathrm{WUE}_{\text {biomass }}$ [13]. Under water-limited conditions crops only assimilate carbon when evaporative demand is low, hence loses less water per carbon gained [13].

Similarly, WUE $E_{\text {intrinsic }}$ was higher under water stressed conditions due to differences in the rate of decrease between $A$ and $g s$. When stomata are partially closed, the photosynthetic rate does not immediately decrease, resulting in higher $W_{U E} E_{\text {intrinsic }}[6]$. Also, WUE $E_{\text {intrinsic }}$ increases when $A$ increases at a constant $g s$ [21]. There was no significant relationship between $W_{U E} E_{\text {biomass }}$ and $W_{U E} E_{\text {intrinsic, }}$ probably because WUE $E_{\text {intrinsic }}$ is an instantaneous measurement that reflects conditions prevailing at the instant of measurement while WUE biomass is an integration of the conditions from sowing to the time of biomass sampling. $\delta^{13} \mathrm{C}$, which provides an integration of $\mathrm{WUE}_{\text {intrinsic }}$ overtime was positively related to $W U E_{\text {biomass }}$ in 2015. The strong relationship shows that $\delta^{13} C$ can be used as a surrogate of $\mathrm{WUE}_{\text {intrinsic }}$ in cowpea. Similar conclusions have also been drawn in other studies [31]. 


\section{Conclusions}

In conclusion, the findings of this study showed that $g s$ responded to genotypic variation, moisture levels and to the time of measurement. Variation in genotypes varied at early vegetative stages and mostly under water-limited conditions, with genotype TVu4607 (TV2) showing much higher gs under SD. As expected, $g s$ was higher under well-watered conditions compared to water-limited conditions but it was interesting to note that, $g s$ still decreased with DAP even under WW conditions. This study also showed that $g s$ is severely restricted in cowpea grown in semi-arid areas as $g s$ under MD and SD were mostly below $0.10 \mathrm{~mol} \mathrm{~m}^{-2} \mathrm{~s}^{-1}$. Thus, improving $g s$ of cowpea grown in such areas could improve its productivity. The use of $\delta^{13} \mathrm{C}$ in screening for high WUE in cowpea maybe limited as it only responded to moisture level and not to genotype. However, the highly significant and positive relationship observed between $\delta^{13} \mathrm{C}$ and $g s$ under SD suggest that $\delta^{13} \mathrm{C}$ could be useful as a screening trait for higher $g s$ in cowpea under drought conditions.

The findings of this study were however constrained by the high rainfall received later in 2016 that reduced the moisture levels to two, thus failing to completely replicate the four levels observed in 2015. Another limitation of the study is in the reduced number of gas exchange measurements $(g s, A, E$ and $c i / c a)$ taken per plot. These are instantaneous measurements that would require several measurements per plot. However, due to the large number of the experimental plots and the limitation in the time and conditions to which measurements can be carried out, a reduced number of measurements per plot were taken to accommodate all plots within the recommended period.

Acknowledgments: This work was financially supported by VLIR-IUC, an Inter University Cooperation with University of Limpopo (UL), South Africa under Project 6 on Food Security. The authors would also like to acknowledge support from the Risk and Vulnerability Science Centre at UL. The following people are also acknowledged for their contribution to the work: Katja Van Nieuland, LouisEloff, and Jimmy Motloutsi.

Author Contributions: Lawrence Munjonji, Kingsley K. Ayisi, Pascal Boeckx and Geert Haesaert conceived and designed the experiments; Lawrence Munjonji performed the experiments; Lawrence Munjonji analyzed the data; Lawrence Munjonji, Kingsley K. Ayisi, Pascal Boeckx and Geert Haesaert contributed towards the writing and editing of the paper.

Conflicts of Interest: The authors declare no conflict of interest.

\section{Appendix A}

A

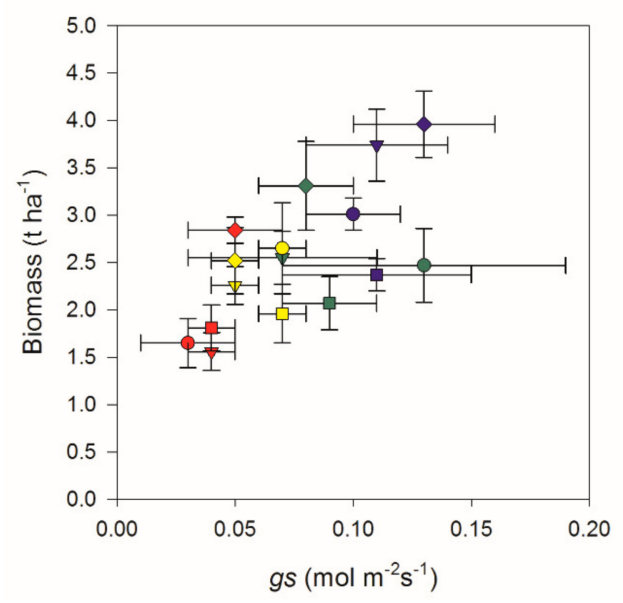

B

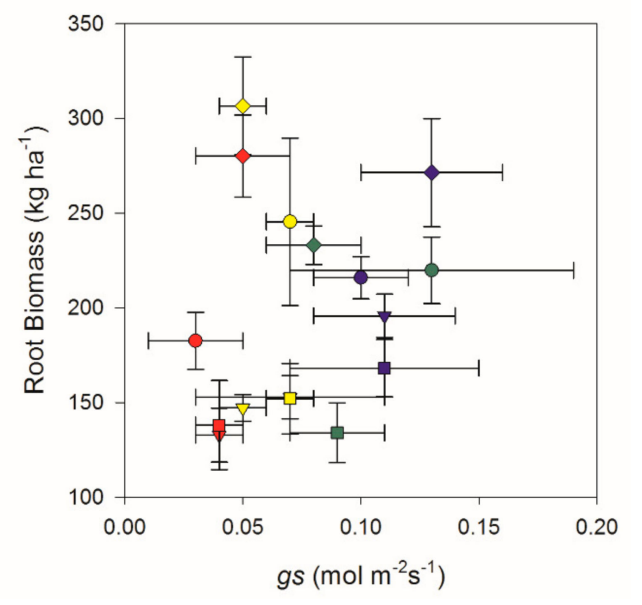

Figure A1. Cont. 
C

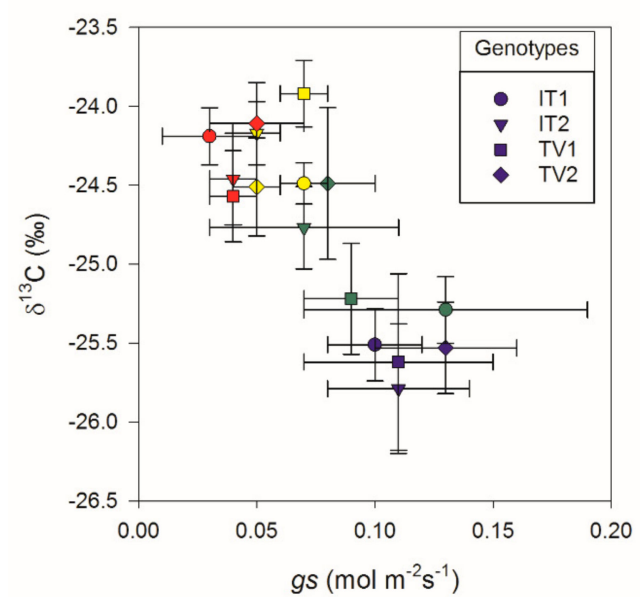

D

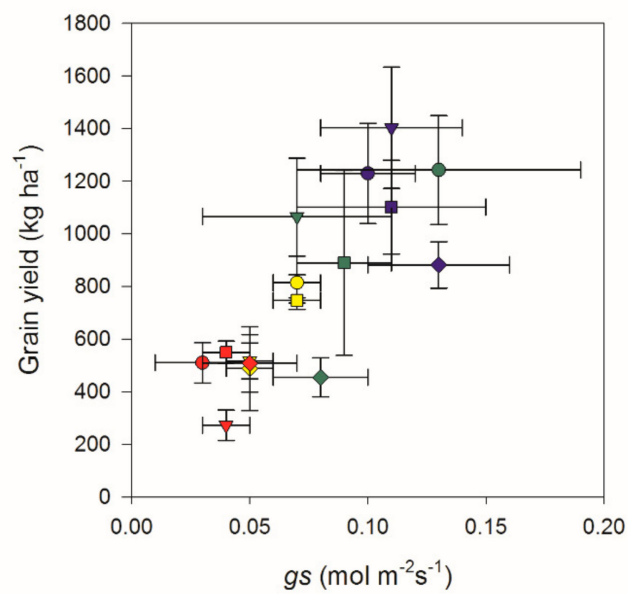

Figure A1. The relationship between genotypic means of stomatal conductance ( $g s)$ measured at $70 \mathrm{DAP}$ and mean biomass (A), root biomass (at flowering) $(\mathbf{B}), \delta^{13} \mathrm{C}(\mathbf{C})$ and grain yield (D). Means were calculated per moisture level i.e., blue for well-watered; green for moderate well-watered; yellow for moderate drought and red for severe drought. Symbols: circle for genotype IT1, triangle for IT2, rectangle for TV1, and diamond for TV2.

\section{References}

1. Farooq, M.; Wahid, A.; Kobayashi, N.; Fujita, D.; Basra, S. Plant Drought Stress: Effects, Mechanisms and Management. Agron. Sustain. Dev. 2009, 29, 185-212. [CrossRef]

2. Farquhar, G.D.; Sharkey, T.D. Stomatal conductance and photosynthesis. Annu. Rev. Plant Physiol. 1982, 33, 317-345. [CrossRef]

3. Lawson, T.; Blatt, M.R. Stomatal size, speed, and responsiveness impact on photosynthesis and water use efficiency. Plant Physiol. 2014, 164, 1556-1570. [CrossRef] [PubMed]

4. Lobell, D.B.; Burke, M.B.; Tebaldi, C.; Mastrandrea, M.D.; Falcon, W.P.; Naylor, R.L. Prioritizing climate change adaptation needs for food security in 2030. Science 2008, 319, 607-610. [CrossRef] [PubMed]

5. Barnabás, B.; Jäger, K.; Fehér, A. The effect of drought and heat stress on reproductive processes in cereals. Plant Cell Environ. 2008, 31, 11-38. [CrossRef] [PubMed]

6. Ninou, E.; Tsialtas, J.; Dordas, C.; Papakosta, D. Effect of irrigation on the relationships between leaf gas exchange related traits and yield in dwarf dry bean grown under mediterranean conditions. Agric. Water Manag. 2012, 116, 235-241. [CrossRef]

7. Mott, K.A.; Buckley, T.N. Stomatal heterogeneity. J. Exp. Bot. 1998, 49, 407-417. [CrossRef]

8. Mott, K.A.; Buckley, T.N. Patchy stomatal conductance: Emergent collective behaviour of stomata. Trends Plant Sci. 2000, 5, 258-262. [CrossRef]

9. Hall, A.E. Phenotyping cowpeas for adaptation to drought. Front. Physiol. 2012, 3, 155. [CrossRef] [PubMed]

10. Condon, A.; Richards, R.; Rebetzke, G.; Farquhar, G. Improving intrinsic water-use efficiency and crop yield. Crop Sci. 2002, 42, 122-131. [CrossRef] [PubMed]

11. Tambussi, E.; Bort, J.; Araus, J. Water use efficiency in $\mathrm{C} 3$ cereals under mediterranean conditions: A review of physiological aspects. Ann. Appl. Biol. 2007, 150, 307-321. [CrossRef]

12. Farquhar, G.; Richards, R. Isotopic composition of plant carbon correlates with water-use efficiency of wheat genotypes. Funct. Plant Biol. 1984, 11, 539-552. [CrossRef]

13. Bloch, D.; Hoffmann, C.M.; Märländer, B. Impact of water supply on photosynthesis, water use and carbon isotope discrimination of sugar beet genotypes. Eur. J. Agron. 2006, 24, 218-225. [CrossRef]

14. WRB. World Reference Base for Soil Resources 2014. In International Soil Classification System for Naming Soils and Creating Legends for Soil Maps; World Soil Resources Reports; FAO: Rome, Italy, 2014.

15. Saxton, K.E.; Rawls, W.J. Soil water characteristic estimates by texture and organic matter for hydrologic solutions. Soil Sci. Soc. Am. J. 2006, 70, 1569-1578. [CrossRef] 
16. Gomez, K.A.; Gomez, A.A. Statistical Procedures for Agricultural Research; John Wiley \& Sons: Toronto, ON, Canada, 1984.

17. Flexas, J.; Bota, J.; Cifre, J.; Mariano Escalona, J.; Galmés, J.; Gulías, J.; Lefi, E.K.; Florinda Martinez-Canellas, S.; Teresa Moreno, M.; Ribas-Carbo, M. Understanding down-regulation of photosynthesis under water stress: Future prospects and searching for physiological tools for irrigation management. Ann. Appl. Biol. 2004, 144, 273-283. [CrossRef]

18. Agbicodo, E.; Fatokun, C.; Muranaka, S.; Visser, R. Breeding drought tolerant cowpea: Constraints, accomplishments, and future prospects. Euphytica 2009, 167, 353-370. [CrossRef]

19. Munjonji, L.; Ayisi, K.K.; Boeckx, P.; Haesaert, G. Screening cowpea genotypes for high biological nitrogen fixation and grain yield under drought conditions. Agron. J. 2017, in press.

20. Anyia, A.; Herzog, H. Water-use efficiency, leaf area and leaf gas exchange of cowpeas under mid-season drought. Eur. J. Agron. 2004, 20, 327-339. [CrossRef]

21. Singh, S.K.; Raja Reddy, K. Regulation of photosynthesis, fluorescence, stomatal conductance and water-use efficiency of cowpea (Vigna unguiculata [L.] Walp.) under drought. J. Photochem. Photobiol. B Biol. 2011, 105, 40-50. [CrossRef] [PubMed]

22. Austin, R.; Craufurd, P.; Hall, M.; Acevedo, E.; da Silveira Pinheiro, B.; Ngugi, E. Carbon isotope discrimination as a means of evaluating drought resistance in barley, rice and cowpeas. Bull. Soc. Bot. Fr. Actual. Bot. 1990, 137, 21-30. [CrossRef]

23. Makoi, J.; Chimphango, S.; Dakora, F. Photosynthesis, water-use efficiency and $\delta 13 C$ of five cowpea genotypes grown in mixed culture and at different densities with sorghum. Photosynthetica 2010, 48, 143-155. [CrossRef]

24. Rivas, R.; Falcão, H.M.; Ribeiro, R.V.; Machado, E.C.; Pimentel, C.; Santos, M.G. Drought tolerance in cowpea species is driven by less sensitivity of leaf gas exchange to water deficit and rapid recovery of photosynthesis after rehydration. S. Afr. J. Bot. 2016, 103, 101-107. [CrossRef]

25. Sikder, S.; Foulkes, J.; West, H.; De Silva, J.; Gaju, O.; Greenland, A.; Howell, P. Evaluation of photosynthetic potential of wheat genotypes under drought condition. Photosynthetica 2015, 53, 47-54. [CrossRef]

26. Liu, F.; Andersen, M.N.; Jacobsen, S.-E.; Jensen, C.R. Stomatal control and water use efficiency of soybean (Glycine max L. Merr.) during progressive soil drying. Environ. Exp. Bot. 2005, 54, 33-40. [CrossRef]

27. Cabrera-Bosquet, L.; Molero, G.; Nogues, S.; Araus, J.L. Water and nitrogen conditions affect the relationships of Delta C-13 and Delta O-18 to gas exchange and growth in durum wheat. J. Exp. Bot. 2009, 60, 1633-1644. [CrossRef] [PubMed]

28. Wang, Y.; Zhang, X.; Liu, X.; Zhang, X.; Shao, L.; Sun, H.; Chen, S. The effects of nitrogen supply and water regime on instantaneous WUE, time-integrated WUE and carbon isotope discrimination in winter wheat. Field Crop. Res. 2013, 144, 236-244. [CrossRef]

29. Araus, J.; Slafer, G.; Reynolds, M.; Royo, C. Plant breeding and drought in C3 cereals: What should we breed for? Ann. Bot. 2002, 89, 925-940. [CrossRef] [PubMed]

30. Erice, G.; Louahlia, S.; Irigoyen, J.J.; Sánchez-Díaz, M.; Alami, I.T.; Avice, J.-C. Water use efficiency, transpiration and net $\mathrm{CO}_{2}$ exchange of four alfalfa genotypes submitted to progressive drought and subsequent recovery. Environ. Exp. Bot. 2011, 72, 123-130. [CrossRef]

31. Barbour, M.M.; Tcherkez, G.; Bickford, C.P.; Mauve, C.; Lamothe, M.; Sinton, S.; Brown, H. $\delta^{13}$ C of leaf-respired $\mathrm{CO}_{2}$ reflects intrinsic water-use efficiency in barley. Plant Cell Environ. 2011, 34, 792-799. [CrossRef] [PubMed]

(C) 2017 by the authors. Licensee MDPI, Basel, Switzerland. This article is an open access article distributed under the terms and conditions of the Creative Commons Attribution (CC BY) license (http://creativecommons.org/licenses/by/4.0/). 